\title{
Successful Desensitization by Post-Centrifugal Plasma Filtration in Two Highly Sensitized Heart and Lung Transplant Recipients
}

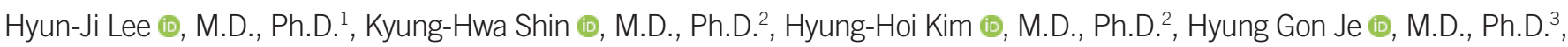

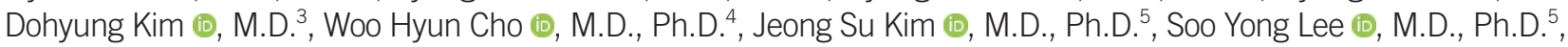
and Hye Ju Yeo (i), M.D., Ph.D. ${ }^{4}$

${ }^{1}$ Department of Laboratory Medicine and Research, Institute for Convergence of Biomedical Science and Technology, Pusan National University Yangsan Hospital, Yangsan, Korea; ${ }^{2}$ Department of Laboratory Medicine, Pusan National University Hospital, Busan, Korea; ${ }^{3}$ Department of Cardiovascular and Thoracic Surgery and Research, Institute for Convergence of Biomedical Science and Technology, Pusan National University Yangsan Hospital, Yangsan, Korea; ${ }^{4}$ Department of Pulmonology and Critical Care Medicine, Pusan National University Yangsan Hospital, Yangsan, Korea; ${ }^{5}$ Division of Cardiology, Department of Internal Medicine and Research, Institute for Convergence of Biomedical Science and Technology, Pusan National University Yangsan Hospital, Pusan National University School of Medicine, Yangsan, Korea

\section{Dear Editor,}

The presence of donor-specific antibodies (DSAs) not only increases the incidence of antibody-mediated rejection (AMR) but also leads to other complications, such as increased frequency of high-grade T cell-mediated rejection, chronic lung allograft dysfunction, bronchiolitis obliterans syndrome, cardiac allograft vasculopathy, and poor allograft survival in heart and lung transplant recipients [1-3]. Sensitized patients have a lower five-year survival rate than non-sensitized patients ( $65 \%$ vs. $74 \%$ ), and rejection occurs more acutely and severely in the former than in the latter [3, 4]. We describe successful desensitization using post-centrifugal plasma filtration (PCPF) in two heart and lung transplant recipients with multiple DSAs. There is no report of desensitization treatment using PCPF in heart and lung transplant recipients. This retrospective study was approved by the Institutional Review Board at Pusan National University Yangsan Hospital, Yangsan, Korea (No. 05-2015-106).

One patient (Case 1, Table 1) was admitted on May 2015 for heart transplantation and showed high levels of four preformed DSAs, with a cumulative mean fluorescence intensity (MFI) of 35,035 at admission. As high DSA levels can predispose to AMR, the patient was desensitized. Two and 10 sessions of PCPF were performed before and after transplantation, respectively, using Com.Tec (Fresenius, Kabi, Germany). The primary plasma separator was a plastic disposable kit (PL1; Fresenius), and the secondary plasma fractionator was a $2 \mathrm{~A}$ column (Evaflux; Asahi Kasei Medical, Japan) with an albumin sieving coefficient of 0.62. To reduce the AMR risk, rituximab, corticosteroid, and bortezomib were administered. Multiple treatments with immunosuppressants and 12 sessions of PCPF reduced the DSA MFI from 35,035 to 4,559 (Fig. 1A). Moreover, only two of the four DSAs were detected. The patient recovered from the rejection episode and was alive on day 1,774 post-transplantation.

Another patient (Case 2, Table 1), a candidate for lung transplantation, admitted on January 2016, presented high levels of
Received: November 5, 2019

Revision received: January 6, 2020

Accepted: March 3, 2020

Corresponding author: Hyung-Hoi Kim, M.D., Ph.D.

Biomedical Research Institute, Pusan National University Hospital Clinical Trial Center (CTC), Department of Laboratory Medicine and Biomedical Informatics Unit of Pusan National University School of Medicine,

1-10 Ami-dong, Seo-gu, Busan 49241, Korea

Tel: +82-51-240-7418, Fax: +82-51-247-6560, E-mail: hhkim@pusan.ac.kr

\section{(c) (1) $(9$}

(C) Korean Society for Laboratory Medicine

This is an Open Access article distributed under the terms of the Creative Commons Attribution Non-Commercial License (https://creativecommons.org/licenses/by-nc/4.0) which permits unrestricted non-commercial use, distribution, and reproduction in any medium, provided the original work is properly cited. 
Table 1. Baseline characteristics of the two patients with DSAs

\begin{tabular}{|c|c|c|c|c|c|c|c|c|c|c|c|c|c|c|c|c|}
\hline \multirow[b]{2}{*}{ Case } & & \multirow{2}{*}{$\begin{array}{l}\text { Age } \\
\text { (yr) }\end{array}$} & \multirow[b]{2}{*}{ Diagnosis } & \multicolumn{3}{|c|}{ Recipient } & \multicolumn{3}{|c|}{ Donor } & \multicolumn{3}{|c|}{ DSA (initial MFI strength) } & \multicolumn{2}{|c|}{ Pre-transplant } & \multicolumn{2}{|c|}{ Outcome (days) } \\
\hline & & & & $\begin{array}{c}\text { HLA } \\
\text { A }\end{array}$ & $\begin{array}{c}\text { HLA } \\
\text { B }\end{array}$ & $\begin{array}{l}\text { HLA } \\
\text { DR }\end{array}$ & $\begin{array}{c}\text { HLA } \\
\text { A }\end{array}$ & $\begin{array}{c}\text { HLA } \\
\text { B }\end{array}$ & $\begin{array}{l}\text { HLA } \\
\text { DR }\end{array}$ & Class I & Class II & $\begin{array}{c}\text { Cumulative } \\
\text { MFI }\end{array}$ & $\begin{array}{l}C D C \\
(\mathrm{~T} / \mathrm{B}) \\
\end{array}$ & $\begin{array}{l}\mathrm{FCM} \\
(\mathrm{T} / \mathrm{B}) \\
\end{array}$ & Rejection & $\begin{array}{l}\text { Alive/ } \\
\text { Dead }\end{array}$ \\
\hline 1 & $\mathrm{~F}$ & 32 & $\begin{array}{l}\text { Dilated } \\
\text { cardiomyopathy }\end{array}$ & $11 / 24$ & $07 / 54$ & $04 / 04$ & $24 / 24$ & $51 / 52$ & $14 / 15$ & $\begin{array}{l}\text { B52 }(9,135), \\
\text { B51 }(2,484)\end{array}$ & $\begin{array}{c}\text { DR14 }(14,616) \\
\text { DR15 }(8,800)\end{array}$ & 35,035 & $\begin{array}{l}\text { Positive/ } \\
\text { Positive }\end{array}$ & $\begin{array}{l}\text { Positive/ } \\
\text { Positive }\end{array}$ & $\begin{array}{l}\text { AMR } \\
\text { episode }\end{array}$ & $\begin{array}{c}\text { Alive } \\
(1,774)\end{array}$ \\
\hline 2 & $\mathrm{~F}$ & 54 & $\begin{array}{l}\text { Acute interstitial } \\
\text { pneumonia }\end{array}$ & | $33 / 33$ & 44/44 & $07 / 13$ & $02 / 11$ & $13 / 48$ & $12 / 14$ & $\begin{array}{c}\text { A2 }(2,752), \\
\text { B48 }(7,093), \\
\text { B13 }(3,079)\end{array}$ & & 12,924 & $\begin{array}{l}\text { Negative/ } \\
\text { Negative }\end{array}$ & $\begin{array}{l}\text { Positive/ } \\
\text { Positive }\end{array}$ & No & $\begin{array}{c}\text { Alive } \\
(1,474)\end{array}$ \\
\hline
\end{tabular}

Abbreviations: AMR, antibody-medicated rejection; CDC, complement-dependent cytotoxicity crossmatch; DSA, donor-specific antibody; FCM, flow cytometry crossmatch; HLA, human leukocyte antigen; MFI, mean fluorescence intensity; T/B, T cell/B cell.
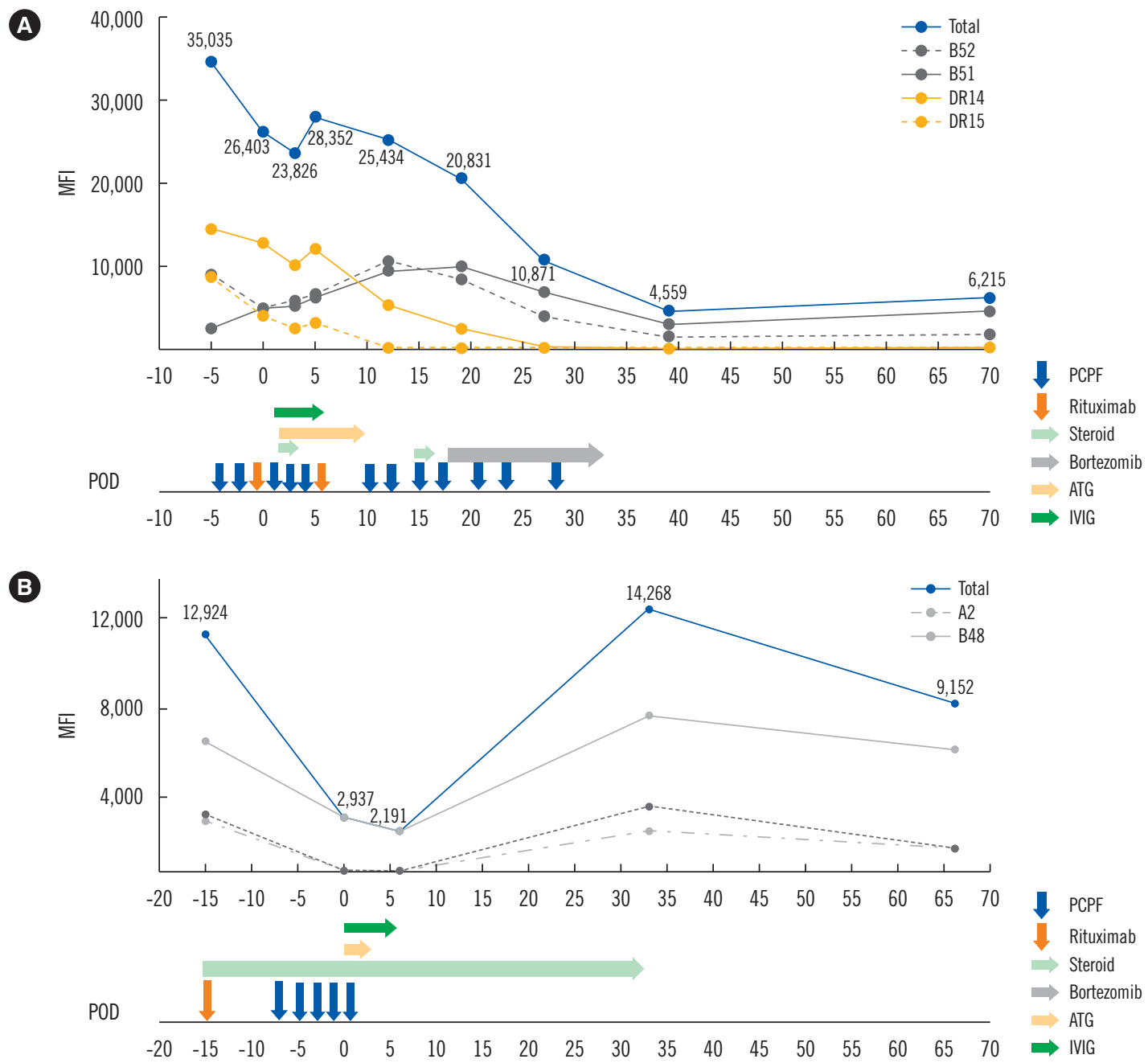

Fig. 1. Changes in DSAs with desensitization treatment. (A) A heart transplant recipient (Case 1, Table 1) with preformed DSAs and (B) a lung transplant recipient (Case 2, Table 1) who underwent desensitization before donor matching.

Abbreviations: ATG, anti-thymocyte globulin; DSA, donor-specific antibody; IVIG, intravenous immunoglobulin; MFI, mean fluorescence intensity; PCPF, post-centrifugal plasma filtration; POD, postoperative day.

46 anti-HLA antibodies (Abs); of these, five showed MFI > 10,000; 27 showed MFI 3,000-10,000, and 14 showed MFI < 3,000 . High DSA levels were predicted for this patient, and ini- tial desensitization with rituximab before and during PCPF was scheduled. Four PCPF sessions were performed before the operation or donor matching to reduce anti-HLA Ab levels. A 
matched donor was found after four sessions of PCPF, and the cumulative MFI of three DSAs decreased from 12,924 to 2,937 on the day of transplantation (Fig. 1B). DSA MFI values increased to 14,268 one month after transplantation, and the patient was subjected to another PCPF session. The patient was alive on day 1,474 post-transplantation.

Rituximab $\left(375 \mathrm{mg} / \mathrm{m}^{2}\right)$ and plasmapheresis should be administered as pre-transplantation treatment to the highly sensitized patients. Intravenous immunoglobulin (IVlg; 1-2 g/ $/ \mathrm{kg}$ ) and anti-thymocyte globulin $(0.75-1.5 \mathrm{mg} / \mathrm{kg}$ ) were administered as induction therapy. Depending on the patient condition, steroids and bortezomib may be administered [3-5]. IVlg therapy is at the core of most desensitization protocols and provides protection against infectious complications [6]. Within one week of IVlg administration, a 33\% decrease in panel-reactive Ab was observed in heart transplant recipients, and a $>80 \%$ reduction in cytotoxicity was achieved with repeated doses [1]. Recently, therapeutic monoclonal Abs have been used to prevent graft rejection [3]. Rituximab, a chimeric anti-CD20 monoclonal Ab, has no effect on plasma cells, but does affect $B$ cells [3]. Therapeutic plasma exchange (TPE) also decreases intravascular lgG levels, with an efficacy comparable to that of IVIg, but it requires a longer treatment period. Bortezomib is a reversible $26 \mathrm{~S}$ proteasome inhibitor that decreases plasma cell levels and has other pleiotropic immunomodulatory effects [6]. Bortezomib treatment reduced alloantibody levels in heart transplant recipients [7]. In this study, two patients with high DSA levels were treated with rituximab and/or bortezomib, with no graft loss. Positive T cell flow cytometry crossmatch is a risk factor for AMR [4]. An MFI of 3,000-5,000, a widely recognized flow cytometry crossmatch-positive cutoff, is considered a target for desensitization treatment [8].

In cases of cadaveric transplantation, the donors are not known in advance, and thus, the desensitization treatment before transplantation is shorter after donor selection. As TPE replaces all plasma, drugs are also removed. Similar to immunoadsorption, PCPF removes only Ig in the plasma that do not pass through the secondary filter. Therefore, it is possible to remove plasma Abs while perpetuating the effects of the drug, which is more effective for desensitization treatment. Our study has some limitations; the treatment method would differ according to the condition of each patient, and owing to the small number of patients, the usefulness of the desensitization protocol could not be statistically validated. In conclusion, we report two patients with high levels of preformed DSAs who underwent PCPF before transplantation. Although the desensitization pe- riod was short owing to the critical condition of the patients, the transplantation was successful. This study shows that successful desensitization in heart and lung transplant recipients can be achieved under favorable circumstances.

\section{ACKNOWLEDGMENTS}

None.

\section{AUTHOR CONTRIBUTIONS}

Conceptualization: HHK. Investigation and data curation: HGJ, DHK, WHC, JSK, SYL and HJY. Writing-original draft preparation and writing: HJL. Writing-review and editing: KHS and HJL. Supervision: HHK. Approval of final manuscript: all authors.

\section{CONFLICTS OF INTEREST}

None declared.

\section{RESEARCH FUNDING}

None declared.

\section{ORCID}

Hyun-Ji Lee https://orcid.org/0000-0002-9021-5632

Kyung-Hwa Shin https://orcid.org/0000-0002-8454-4448

Hyung-Hoi Kim https://orcid.org/0000-0003-3989-2037

Hyung Gon Je https://orcid.org/0000-0003-4713-2898

Dohyung Kim https://orcid.org/0000-0002-8774-3397

Woo Hyun Cho https://orcid.org/0000-0002-8299-8008

Jeong Su Kim https://orcid.org/0000-0001-6877-4289

Soo Yong Lee https://orcid.org/0000-0003-2616-1294

Hye Ju Yeo https://orcid.org/0000-0002-8403-5790

\section{REFERENCES}

1. Al-Mohaissen MA and Virani SA. Allosensitization in heart transplantation: an overview. Can J Cardiol 2014;30:161-72.

2. Li F, Atz ME, Reed EF. Human leukocyte antigen antibodies in chronic transplant vasculopathy-mechanisms and pathways. Curr Opin Immunol 2009;21:557-62.

3. Colvin MM, Cook JL, Chang PP, Hsu DT, Kiernan MS, Kobashigawa JA, et al. Sensitization in heart transplantation: Emerging knowledge: A scientific statement from the American Heart Association. Circulation 2019; 139:e553-78.

4. Colvin MM, Cook JL, Chang P, Francis G, Hsu DT, Kiernan MS, et al. 
Antibody-mediated rejection in cardiac transplantation: emerging knowledge in diagnosis and management: a scientific statement from the American Heart Association. Circulation 2015;131:1608-39.

5. Park BG. Desensitization in HLA incompatible transplantation. Korean J Blood Transfus 2019;30:1-14.

6. Jordan SC, Reinsmoen N, Lai CH, Vo A. Novel immunotherapeutic approaches to improve rates and outcomes of transplantation in sensitized renal allograft recipients. Discov Med 2012;13:235-45.

7. Patel J, Everly M, Chang D, Kittleson M, Reed E, Kobashigawa J. Reduction of alloantibodies via proteasome inhibition in cardiac transplantation. J Heart Lung Transplant 2011;30:1320-6.

8. Iyer HS, Jackson AM, Zachary AA, Montgomery RA. Transplanting the highly sensitized patient: trials and tribulations. Curr Opin Nephrol Hypertens 2013;22:681-8. 